\title{
Medievalista
}

Online

$25 \mid 2019$

Número 25

\section{Delectare ed prodesse: aventuras, placeres y didactismo en el Conte du Papegau}

Delectare ed prodesse: aventures, pleasure and didactism in the Conte du Papegau

\section{Lidia Amor}

\section{OpenEdition}

\section{Journals}

Edición electrónica

URL: http://journals.openedition.org/medievalista/1745

DOI: 10.4000/medievalista. 1745

ISSN: 1646-740X

\section{Editor}

Instituto de Estudos Medievais - FCSH-UNL

\section{Referencia electrónica}

Lidia Amor, «Delectare ed prodesse: aventuras, placeres y didactismo en el Conte du Papegau »,

Medievalista [En línea], 25 | 2019, Puesto en línea el 17 marzo 2019, consultado el 01 mayo 2019. URL : http://journals.openedition.org/medievalista/1745 ; DOI : 10.4000/medievalista.1745

Este documento fue generado automáticamente el 1 mayo 2019.

(c) IEM 


\section{Delectare ed prodesse: aventuras, placeres y didactismo en el Conte $d u$ Papegau}

Delectare ed prodesse: aventures, pleasure and didactism in the Conte du Papegau

Lidia Amor

\section{NOTA DEL EDITOR}

Data recepção do artigo / Received for publication: 24-06-2018

Data aceitação do artigo / Accepted in revised form: 07-12-2018

\section{Interrogantes y sorpresas en un relato de mocedades}

1 El Conte du Papegau, relato francés de fines del siglo XIV o principios del XV, narra las aventuras que el rey Arturo decide emprender el día de su coronación. En la primera justa de la cual participa, conquista un papagayo, ave locuaz que lo acompañará en su periplo de maravillas y encuentros amorosos. Más allá del encanto que ejerce una (nueva) historia del mítico monarca bretón, ciertas incógnitas despiertan la curiosidad del medievalista. Se han señalado, en principio, dos cuestiones: por un lado, la limitada difusión del Conte - dado que se conserva únicamente en un manuscrito y no se hallan testimonios en impresos posteriores - y, por el otro, su carácter inaugural, pues se presenta como un relato de infancias, en el cual el anciano soberano muestra, de manera retrospectiva, su talento caballeresco frente a oponentes excepcionales.

Respecto de la transmisión textual del Conte du Papegau, Hélène Charpentier y Patricia Victorin, especialistas a cargo de la edición moderna bilingüe ${ }^{1}$, mencionan una serie de 
agregados, al final del manuscrito existente, que permite conocer a sus propietarios. Los nombres consignados hacen referencia a las damas de la familia Tournon ${ }^{2}$. Estos datos nos informan, sin embargo, acerca de una "lectura" tardía del texto, ya que estas mujeres vivieron en las primeras décadas del siglo XVI. Si las únicas huellas conservadas refieren un auditorio femenino, esta circunstancia supone una contradicción, pues, a partir de ciertas marcas discursivas, a las que me referiré en páginas siguientes, podría afirmarse que el Conte estuvo destinado a un lector ideal joven y masculino.

No obstante, las dos opciones no son mutuamente excluyentes. En efecto, más allá de la función lúdica que el texto evidentemente persigue, las aventuras que Arturo debe afrontar simbolizan aprendizajes necesarios para cualquier integrante de la orden de caballería y se vinculan, además, con las primeras manifestaciones de la pasión amorosa. En un contexto marcado por una extrema cortesía, Arturo hace gala de fervor guerrero en torneos y justas mientras disfruta de la compañía de bellísimas doncellas, quienes están dispuestas a ofrecerle su amor a cambio de protección. Estas mujeres (habitantes, algunas de ellas, del más allá feérico) son, además, consortes potenciales - siguiendo la tradición del roman artúrico - que necesitan un esposo para administrar sus señoríos. La historia se desarrolla, por ende, en un espacio femenino, en donde ningún pariente (padre, hermano o tío) puede anteponer sus derechos para el ejercicio del poder señorial. Como en la literatura de caballerías pretérita, el relato se construye como metáfora de los deberes y las necesidades de todo joven de la nobleza a punto de ingresar en la vida adulta: entrenarse en la adquisición de saberes guerreros y cortesanos, aprender los principios del gobierno - de sí mismo y de los otros -, encontrar una doncella con una dote importante a quien desposar ${ }^{3}$ y establecerse en sus dominios. Las descripciones, por su parte, exhiben un ambiente de diversiones, donde Arturo y las muchachas gozan de las danzas, de los cantos y de largas noches de amor; entorno de placeres con el cual el papagayo contribuye a través de melodías y narraciones. ¿Es preciso optar por algún receptor o podemos inferir que no existe dicotomía alguna, sino que el relato designa un público heterogéneo, cuyo denominador común es la juventud?

El otro interrogante se circunscribe a la supuesta incoherencia que plantea un relato de mocedades luego de que la Mort Artu determinó no solo la desaparición del rey sino, en particular, el ocaso de su universo (ficcional). En efecto, la Mort Artu estableció un terminus ad quem para los escritores de los siglos XIV y XV que pretendían inscribir sus textos en la tradición narrativa artúrica. Los autores de algunas obras tardías, llamadas “originales" (pues, en principio, no constituyen adaptaciones íntegras de narraciones previas) componen historias fijadas en los márgenes del cronotopo artúrico mientras que sus personajes se conectan, de manera dinástica, con los grandes héroes de la Mesa Redonda, tal como se observa en Perceforest o en Ysä̈e le Triste. La pregunta se vuelve más oportuna pues, como los especialistas puntualizan, Arturo no sale a la aventura para comenzar un proceso de individualización y perfeccionamiento a través del esquema salida, crisis, superación de la crisis y retorno ${ }^{4}$ ni sus acciones forman parte de un Bildungreise $^{5}$. De igual modo, al final de su periplo, el joven monarca no espera ni es recompensado con una esposa y un reino por sus acciones superlativas. Su vuelta a Camelot implica retomar el destino que la leyenda ya había cristalizado. Más aún, la condición regia de Arturo, identificada, primordialmente, con la obligación de gobernar y dirigir los destinos de sus súbditos, estaría reñida con la vida del caballero errante. Un último problema se vincularía con el hecho de que las aventuras son reelaboraciones y reformulaciones de antiguos episodios pertenecientes, entre otros, al Erec et Enide, a Le 
Chevalier au lion y a Le chevalier de la charrette, ${ }^{6}$ circunstancia que privaría al relato de "originalidad".

5 Más allá de las razones que problematizan la presencia de un relato de infancias artúrico en el "ocaso" de su tradición literaria, la idea de discordancia proviene, en realidad, de la inadecuación existente entre la forma textual (una historia de mocedades) y el héroe (Arturo), caracterizado, en las múltiples manifestaciones textuales que nos han llegado, como un hombre maduro. Desde esta óptica, su éxito en los enfrentamientos narrados no implica ni un crecimiento social ni una superación personal. Sin embargo, si consideramos el Conte du Papegau desde la perspectiva de los ciclos (tanto épicos - el ciclo de Guillaume, por ejemplo - como la gran summa artúrica del siglo XIII), la composición tardía de una narración que relate las infancias del héroe no presenta problema alguno. Sabemos que, en líneas generales, los textos que se consagran a historiar la infancia de un héroe se adhieren a un texto o a un conjunto de ellos elaborados previamente, con el objetivo específico de proporcionar, a una materia favorablemente recibida por el auditorio, una nueva relación sobre los primeros años del héroe. En este sentido, resulta evidente que el autor del Conte encontró en el personaje de Arturo, una veta hasta ese momento poco explorada y una ocasión propicia para anclar su roman en el ciclo artúrico del siglo XIII.

6 Las dos lecturas son posibles e implican cierta complementariedad. Ahora bien, es preciso sostener que la ausencia de motivación no afecta la naturaleza iniciática (en el dominio de la sociabilidad, de la caballería y del deseo) del Conte du Papegau. Es, justamente, la fisura entre la idea de aprendizaje y la madurez tradicional del héroe la que permite distinguir el aspecto inaugural de la historia. En esta línea de pensamiento, debemos admitir que la voluntad de instruir no afecta ni caracteriza el personaje, sino que representa el rasgo primordial de la diégesis. En cualquiera de las dos vertientes, cuando utilizo el concepto de iniciación no me refiero a la experiencia vital del héroe, sino que estoy aludiendo al tipo de relato al que se enfrenta el lector, es decir una narración donde se plasman los primeros movimientos del personaje caballeresco en la sociedad a la cual ingresa. Desde esta perspectiva, las aventuras de Arturo deben ser consideradas como la praxis de algunos de los principios de la orden de caballería que los jóvenes deben aprender pues constituyen acciones con una finalidad social (liberar, restaurar, redimir y civilizar) y que anuncian las responsabilidades de todo monarca o señor.

7 En segundo lugar, podría aducirse que la reproducción de episodios provenientes de textos antiguos no implica su repetición asintomática, no solo porque se hallan escindidos de sus contextos originales - enunciado un tanto simplista pero que no carece, por ello, de relevancia ${ }^{7}$ - sino también porque el autor desbarata la idea de copia mediante un cambio temporal. En efecto, el narrador indica, al comienzo del Conte, el rasgo fundacional de su relato: "Et c'est la premiere aventure qui est avenue en vostre court, si vous prie, pour Dieu et pour vostre honneur, que vous luy fácies". Como estamos ante la primera aventura del reino de Logres, estamos, por consiguiente, en el inicio de todas las aventuras y, en consecuencia, la cronología se altera: el pasado se inscribe en el presente de la enunciación mientras que la tradición literaria constituye el futuro de dicha enunciación y se encuentra subordinada a las acciones que se narran en el Conte. En el imaginario que el narrador trata de promover, la salida a la aventura es instituida por Arturo y este accionar será retomado, más tarde, por Erec, Yvain y Lancelot. Así, las proezas de Arturo simbolizan la génesis de toda hazaña caballeresca. 
8 Las dificultades que se han comentado se conectan, a mi entender, con un cuestionamiento acerca del receptor ideal al cual el autor del texto aspiraba. Estos interrogantes pueden ser examinados, en conjunto, mediante un análisis de la intentio autoris subyacente en el Conte, concepto cuyo estudio nos obliga a tener presente ciertas observaciones. Es necesario recordar que, en líneas generales, los textos literarios se escapan de los márgenes pre/provistos por los autores e integran, en numerosas ocasiones, experiencias ajenas a la cognición plena de estos últimos. Somos conscientes también de que el texto se (re)construye en cada lectura (o en cada recepción) y que su significado semeja un caleidoscopio: cada movimiento o lectura implica una percepción diferente que arroja sentidos distintos.

Respecto de las obras medievales, a estas consideraciones se suma la incertidumbre. En efecto, no carece de relevancia conocer la intentio autoris de una obra medieval ya que dicho conocimiento nos permitiría acceder a algunas de las ideas que circularon en una cultura específica. Sin embargo, no es posible, en muchos casos, establecer las señas particulares del autor material o del contexto de producción o del auditorio, circunstancia que las reflexiones precedentes, vinculadas con el público del conte du Papegau corroboran. Por otra parte, sabemos que las obras medievales hacen explícita, muchas veces, su finalidad didáctica o "pasatista", aunque resulta ser poco productivo distribuir los textos entre estas dos opciones porque se establecería una dualidad taxonómica inexistente. Teniendo en cuenta estas observaciones, estimo admisible reconstruir la intentio autoris que organiza un texto si la consideramos como la marca de un proceso dialéctico mediante el cual un conjunto de fuerzas sociales convergen y modelan la experiencia de vida del autor, su percepción de la realidad y de los constructos sociales y culturales que lo rodean. Dicha experiencia se vuelve significativa cuando se actualiza $^{9}$ en la arquitectura del texto y produce, en el receptor, la empatía y la identificación. Por su parte, el texto incide sobre las representaciones sociales y se halla en el origen de ciertas conductas o manifestaciones culturales. En consecuencia, la obra constituye uno de los múltiples intersticios donde coinciden mínimas unidades de sentido, indicadoras tanto de prácticas compartidas como de un pacto de lectura (entre el autor y el receptor - por intermedio del texto - y entre los integrantes del auditorio). El autor sería un médium que traduce los códigos semióticos que gobiernan las representaciones sociales al código semiótico que rige la representación lingüística de la realidad percibida. De esta manera podríamos recobrar el posible significado histórico y la dimensión social de las obras medievales al tiempo que estaríamos imprimiendo nuestra intelección de ese pasado a través de la exégesis hecha sobre dicho texto. Desde esta perspectiva, en última instancia, es pertinente buscar, en el discurso literario, las huellas de una experiencia de vida, una sensación de época (o aquello que se introduce allí como tales) sin caer en la trampa de suponer que estamos ante los hechos verdaderos.

10 A partir de estos parámetros, el propósito de este artículo es demostrar que, pese a su carácter ficcional, en el Conte du Papegau prima la función didáctica. En efecto, el autor organizó temas y motivos - legados por la tradición - y, mediante el empleo de algunos de los recursos de las artes praedicandi logró que el roman integrara el conjunto de obras destinadas a enseñar moral y ética a un receptor joven y noble que ingresa en la adultez y se inicia en la vida social. Así, bajo la máscara de la diversión, se escondería una voluntad pedagógica que se hace eco, en la época dominada por los specula principum y por los textos didácticos, de las amonestaciones de los intelectuales a la nobleza y a la caballería. Para tal fin, el autor modeló la materia que más atraía a los jóvenes nobles, ideó una 
historia poblada únicamente por ellos y representó sus vivencias $\mathrm{y}$, en especial, sus deseos. Más aún, el papagayo, cuya voz desbordante y pletórica duplica la narración y la colma de vitalidad, colabora con la identificación del destinatario: el comportamiento del ave recuerda, en su inconstancia, la frivolidad característica de la juventud, de acuerdo con la mirada que los mayores, de todas las épocas, han depositado sobre donceles y damiselas.

\section{Seducir e ilustrar al joven señor. de la aventura maravillosa al exemplum}

Hélène Charpentier y Patricia Victorin ${ }^{10}$, siguiendo los comentarios de Danielle RégnierBohler ${ }^{11}$, han sugerido que el Conte du Papegau conforma una colección de historias artúricas similar al Chastoiement d'un père à son fils. Han llamado la atención, asimismo, sobre el aspecto paratáctico del relato y el carácter gnómico del discurso ${ }^{12}$. Por su parte, Elizabeth Gaucher ${ }^{13}$ explica que Arturo posee una doble figura en este conte: por un lado, constituye un personaje biográfico que imaginamos ya anciano o poseedor de una rica experiencia y, por el otro, representa un lector todavía joven, integrante del público aristocrático. Comenta, asimismo, que la compilación y la copia de antiguos episodios de la narrativa artúrica encuentran un eco en el psitacismo del papagayo; explica que el relato se sustenta en un juego de la memoria mediante el cual los clásicos se reiteran, a la manera de esa poética del discontinuo, propia de los cronistas y los rhétoriqueurs del siglo $\mathrm{XV}$ y de los populares entremeses de los festines borgoñones.

En mi opinión, esta suerte de poética de la parataxis y la inserción de una palabra sentenciosa encubren la apropiación y asimilación, como adelanté, de algunas de los recursos de las artes praedicandi. Más aún, a partir de esta constatación, pongo el acento en los posibles usos que el autor del Conte du Papegau pudo haber hecho de las colecciones de exempla, como la Disciplina clericalis, obra de la cual el Chastoienement d'un père à son fils es una adaptación. En efecto, el relato del Conte se dispone como una yuxtaposición continua de aventuras que culminan, la mayoría de ellas, con una sentencia de la cual extraer una moral ${ }^{14}$, como se observa en el cuadro que se incluye a continuación. De esta forma, la narración parece emular aquellas partes del sermón en las cuales el exemplum se utiliza para transmitir, de manera accesible, el tema de adoctrinamiento.

\begin{tabular}{|l|l|}
\hline Aventura & Finalidad \\
\hline $\begin{array}{l}\text { Auxilio a la Dame des Cheveux Blons del } \\
\text { ataque de un caballero (Chevalier Poisson) }\end{array}$ & Liberación de ser sobrenatural \\
\hline $\begin{array}{l}\text { Auxilio dama a punto de ser asesinada por } \\
\text { caballero celoso }\end{array}$ & $\begin{array}{l}\text { Auxilio de la mujer } \\
\text { Redención de caballero celoso }\end{array}$ \\
\hline $\begin{array}{l}\text { Justa del Papagayo } \\
\text { Episodio de la carreta }\end{array}$ & $\begin{array}{l}\text { Liberación de una Mala Costumbre } \\
\text { Castigo a Lion sans Mercy }\end{array}$ \\
\hline Combate contra el Chevalier Poisson & Liberación de ser sobrenatural \\
\hline
\end{tabular}




\begin{tabular}{|c|c|}
\hline $\begin{array}{l}\text { Torneo organizado por la Dame des Cheveux } \\
\text { Blons. }\end{array}$ & $\begin{array}{l}\text { TRÍADA GNÓMICA: } \\
\text { TROIS FOLX SONT PAR LE MONDE }\end{array}$ \\
\hline $\begin{array}{l}\text { Llegada doncella de Flor de Mont al castillo } \\
\text { de la Dame des Cheveux Blons }\end{array}$ & $\begin{array}{l}\text { Rescatar a una doncella de un señor/súbdito } \\
\text { abusivo. Liberación y restauración del Orden }\end{array}$ \\
\hline $\begin{array}{l}\text { Anuncio del torneo duquesa de Outre-Galles } \\
\text { Justa en el bosque contra el Chevalier Jayant }\end{array}$ & $\begin{array}{l}\text { TRÍADA GNÓMICA: } \\
\text { TROIS SENS SONT AU MONDE }\end{array}$ \\
\hline \multicolumn{2}{|c|}{ Venganza del hermano del Chevalier Jayant contra la duquesa de Outre Galles } \\
\hline $\begin{array}{l}\text { Arturo llega a las posesiones de Flor de } \\
\text { Mont }\end{array}$ & Liberación y Restauración del orden social \\
\hline Inicio de la aventura maravillosa & $\begin{array}{l}\text { TRÍADA GNÓMICA: } \\
\text { TROIS MESAVENTURES SONT } \\
\text { EN CE MONDE }\end{array}$ \\
\hline Fin de la aventura maravillosa & $\begin{array}{l}\text { Población Liberada } \\
\text { TRÍADA GNÓMICA: } \\
\text { TROIS DOULEURS SONT DONNEES } \\
\text { EN CE MONDE }\end{array}$ \\
\hline $\begin{array}{l}\text { Encuentro con el enano y el gigante en la } \\
\text { isla }\end{array}$ & Civilizar y restituir al mundo social \\
\hline
\end{tabular}

Dado que el objetivo pedagógico comanda la arquitectura misma del relato, en esta línea es posible comprender las características más llamativas del Conte: 1) la presencia de Arturo como héroe caballeresco; 2) la autosuficiencia y la autoreferencialidad de los motivos, las cuales sustentan el rasgo paratáctico de la narración; 3) el aspecto gnómico del discurso que funciona como coda de cada aventura y 4) la variedad de elementos que constituyen los hechos sobrenaturales en el relato, los cuales ponen de manifiesto un fuerte sincretismo entre las maravillas de Bretaña y los saberes enciclopédicos. Así, mediante un modelado meticuloso de la materia ficcional bajo las formas de la predicación, las aventuras se postulan como exempla a partir de los cuales el receptor debe sacar una enseñanza. En esta oportunidad, me detendré a desarrollar algunas reflexiones preliminares en torno a dos de los ítems enumerados, relativos a la elección del protagonista y de los episodios que constituyen el relato.

Considero de utilidad iniciar este breve estudio con la definición de exemplum que nos proporciona Juan de Garlandia: "[...] dictum vel factum alicuius autentice persone dignum imitatione"15. Podría afirmarse, siguiendo a Juan de Garlandia, que el carácter modélico de quien habla o actúa brinda ejemplaridad a sus palabras y a sus acciones ${ }^{16} \mathrm{y}$ las postula como meritorias para ser emuladas por las personas comunes. En el caso que nos ocupa y presuponiendo el círculo en el cual se difunde este relato, la voluntad didáctica esclarecería la reelaboración de los motivos ${ }^{17}$ más sobresalientes de la narrativa artúrica previa bajo la actuación de Arturo. En efecto, el autor pudo haber escogido al legendario rey como protagonista de un conjunto de aventuras, ya presentes en relatos anteriores, 
porque resultaba ser un modelo al cual debía aspirar todo joven noble. Desde esta perspectiva, cobra relevancia el hecho de que las aventuras que Arturo enfrenta poseen un matiz tanto lúdico como social, pues se trata de actos que redundan en beneficio de los débiles, de los necesitados y de caballeros renegados, quienes serán reintegrados, luego de recibir las amonestaciones del joven rey-caballero, al mundo de los caballeros probos.

En definitiva, la reproducción de episodios bajo el protagonismo de Arturo permite conjugar la intención pedagógica (i.e., enseñar un modelo de conducta) con el entretenimiento ${ }^{18}$, hecho que nos informa, además, sobre los gustos literarios de los receptores de la Edad Media tardía y sobre la pervivencia vital del pasado en las obras del presente. La serie de transformaciones experimentadas por dichos episodios produce el extrañamiento en el receptor ya que el cotejo del "original" con la "copia" permite notar, claramente, las diferencias. Las divergencias, asimismo, logran aumentar el placer de la lectura a través de la variante, aseguran la captatio benevolentiae y autorizan a que la intención moralizante de la aventura se torne explícita. Por último, el aspecto didáctico de la aventura-exemplum se manifiesta doblemente a través de la voz admonitoria que clausura cada episodio y que se impone como contrapunto de la voz del papagayo. En este sentido, la voz autoral se deslizará, a través de la voz narradora, para educar a los receptores.

16 Es sabido que el carácter modélico de Arturo estuvo determinado por las virtudes que definieron su imagen en la mentalidad nobiliaria francesa desde el siglo XII. Sin embargo, podría afirmarse también que el autor del Conte se apoyó parcialmente en dicha fama y que prefirió representar a Arturo como un modelo ideal en devenir, exhibiendo el proceso a través del cual se iba construyendo en el joven soberano su capacidad de gobernar un grupo humano. Las acciones, en consecuencia, no dependen de la imagen regia cristalizada, sino que nos hallamos ante un personaje en desarrollo, el cual pone en práctica un accionar tendiente a mejorar el mundo circundante y cuya figura juvenil es más fácil de emular por un joven a punto de ingresar en la etapa adulta.

Desde esta perspectiva, la imagen tradicional de Arturo, vinculada con el modelo del dominus, se eclipsa, momentáneamente, ante la figura del caballero. En este contexto, las aventuras son un preludio de la misión real, por cuanto liberar, redimir, restaurar y civilizar son variantes del mantenimiento del bien común. Esta idea encuentra un sustento adicional en la ambigüedad cronológica del relato y en el rasgo bifronte de Arturo, el de puer senex, ideal de los moralistas medievales. Mediante este rasgo del protagonista, duplicado en la inestabilidad temporal de la historia, se introduce, de forma simultánea, los términos a quo y ad quem que delimitan el periodo de la adolescencia ${ }^{19}$ : desde el comienzo de un aprendizaje social hasta el último estadio al cual debe llegarse antes de acceder a una posición de responsabilidad. En última instancia, las aventuras se disponen para mostrar, de manera reiterativa, este proceso de maduración social del joven.

\section{Algunas reflexiones conclusivas}

El estudio de los escasos textos artúricos conservados provenientes de los siglos XIV y XV origina cierto desconcierto. Se constata que, a pesar de las críticas de los medievalistas sobre el carácter reiterativo y poco original de esta literatura, es posible observar en ella algunas transformaciones en su poética que permiten singularizarla, en el nivel diacrónico, respecto de las manifestaciones anteriores. Se comprueba, además, que los 
textos tardíos exacerban la inestabilidad genérica que atenta contra toda voluntad de taxonomía y que implica, no obstante, un dialogismo enriquecedor con formas textuales que le son contemporáneas. Esta constatación supone, además, que la dualidad copiamodificación con la que se evalúa las transformaciones poéticas de los textos resultaría ser insuficiente para explicar la variación constante de los fenómenos literarios. En mi opinión, si bien la reproducción de motivos y episodios constituye el rasgo que más ha identificado la producción tardía, existe, no obstante, una variante fundamental que depende y procede de la intentio autoris.

En efecto, en una breve sinopsis de la tradición literaria de materia artúrica francesa, es posible observar que las obras de Chrétien de Troyes pudieron servir para sublimar las aspiraciones de una nobleza débil o para proveerlos de una ideología a la cual recurrir para exaltar el valor del grupo. Sin embargo, estas cuestiones se enlazaban con otras intenciones de los autores, relacionadas con la voluntad de explorar nuevos senderos poéticos en la encrucijada entre la preceptiva clásica y las nuevas formas de componer en lengua vernácula. Contrario a ello, los textos artúricos de los siglos XIV y XV no ponen de manifiesto una búsqueda poética, sino que parecen haber sido compuestos como espejos donde reflejar una visión de mundo que reproduce los valores éticos de una clase y cuya "imagen de grupo" deviene materia de adoctrinamiento. En esta línea, la reproducción de motivos brinda espesor histórico y naturaliza esa concepción de linaje nobiliario. Desde los parámetros éticos-ideológicos enunciados, se explica y se conforma el mundo que es necesario aprehender y dominar. La distancia entre la búsqueda de una poética propia y un uso utilitario de la literatura de ficción, dos fenómenos dependientes de la intentio autoris, produce la transformación formal de los textos.

Lejos quedó la experimentación literaria del siglo XII como motor principal de la escritura poética, la nobleza finisecular es la primera en reconocer el poder ideológico y cohesivo de la fantasía y comanda, al grupo de escritores-funcionarios bajo su órbita, que brinden todo su saber a la preservación de dicha ideología.

\section{BIBLIOGRAFÍA}

Fuentes impressas

Le Conte du Papegau. Ed., trad. y notas de Hélène Charpentier y Patricia Victorin. Paris: Champion, 2004.

The Parisiana Poetria of John of Garland. Ed. y trad. Traugott Lawler. New Haven: Yale University Press, 1974.

Estudios

BREMOND, Claude; LE GOFF, Jacques - L'exemplum. Turnhout: Brepols, 1982. (Typologie des sources du moyen âge occidental). 
GAUCHER, Elizabeth - “Le chevalier au papegau; 'enfances' ou déclin de la littérature arthurienne?”. in HÜE, Denis; FERLAMPIN-ACHER, Christine. (Eds.) - Enfances arthuriennes. Actes $d u 2^{e}$ colloque arthurien de Rennes, 6-7 mars 2003. Orléans: Paradigme, 2006, pp. 255-268.

REGNIER-BOHLER, Danielle - “Arthur en enfances (Le Chevalier au Papegau)”. PRIS-MA 13 (1997), pp. 91-106.

SHAHAR, Shulamith - Childhood in the Middle Ages. London: Routledge, 1992.

TAYLOR, Jane H. M. - "The knight and the parrot: writing the quest at the end of the Middle Ages". in LACY, Norris J. (Ed.) - The fortunes of king Arthur. Cambridge: D.S. Brewer, 2005, pp. 181-194.

TAYLOR, Larissa J. - “French sermons, 1215-1535”. in MAYNE KIENZLE, B. (Ed.) - The sermon. Turnhout: Brepols, 2000, pp. 711-758.

\section{NOTAS}

1. Le Conte du Papegau. Ed., trad. y notas de Hélène Charpentier y Patricia Victorin. Paris: Champion, 2004.

2. Le Conte du Papegau. Ed., trad. y notas de Hélène Charpentier y Patricia Victorin, p. 10.

3. Los adversarios contra quienes Arturo combate son presa del amor y, en especial, de los celos; pero lejos de manifestar las experiencias de la fin'amors, la posesión de la amada significa concertar alianzas matrimoniales, tema que el episodio del torneo organizado por la duquesa de Outre-Galles expresa de manera emblemática.

4. “Comme il n'y a nul risque hormis celui, très convenu, de se faire battre par un adversaire redoutable, nulle énigme perçue comme telle, nulle crise, nulle identité mise en cause, nul engagement et nulle promesse non tenue, Arthur ne saurait s'aligner sur les chevaliers en quête d'eux-mêmes". REGNIER-BOHLER, Danielle - "Arthur en enfances (Le Chevalier au Papegau)”. PRIS-MA 13 (1997), pp. 91-106, p. 98.

5. TAYLOR, Jane H. M. - "The knight and the parrot: writing the quest at the end of the Middle Ages". in LACY, Norris J. (Ed.) - The fortunes of king Arthur. Cambridge: D.S. Brewer, 2005, pp. 181-194.

6. La referencia directa de Chrétien de Troyes no es la única relación que el autor establece con textos previos. El roman en verso del siglo XIII se halla también representado en este texto. Véase Le Conte du Papegau. Ed., trad. y notas de Hélène Charpentier y Patricia Victorin, p. 12.

7. En mi opinión, el cambio de contexto afecta la significación del episodio mientras que el recuerdo del significado anterior no se contrapone sino que se adiciona, amplificando el alcance semántico del motivo.

8. Las bastardillas en el texto son mías. "Y es la primera aventura que llega a vuestra corte, os pido, por Dios y por vuestro honor, que la emprendáis" [la traducción es mía].

9. Utilizo el significado de acuerdo con la acepción lingüística del vocablo propuesta por el DRAE [Diccionario de la lengua española de la Real Academia Española]: "hacer que elementos lingüísticos abstractos o virtuales se conviertan en concretos e individuales, constituyendo mensajes inteligibles".

10. Le Conte du Papegau. Ed., trad. y notas de Hélène Charpentier y Patricia Victorin.

11. REGNIER-BOHLER, Danielle - "Arthur en enfances".

12. "Dans le Papegau, en revanche, à défaut d'une parole auctoriale omniprésente, on trouve, d'une part, une parole gnomique et sentencieuse sous la forme de "triades morales", et d'autre part, la parole ludique et lyrique du papegau, que commente ou chante les aventures et les 
exploits de son chevalier. L'insertion des sentences disposées en triade permet d'apporter une seconde fin au récit de l'aventure, selon le procédé de la double clausule propre aux récits brefs. Ces paroles sentencieuses passent d'un locuteur à un autre, d'un destinataire à un autre; la morale de l'histoire peut ainsi être prise en charge indifféremment par l'adversaire du héros, un auxiliaire ou un simple 'utilité"'. Le Conte du Papegau. Ed., trad. y notas de Hélène Charpentier y Patricia Victorin, p. 19.

13. GAUCHER, Elizabeth - "Le chevalier au papegau; 'enfances' ou déclin de la littérature arthurienne?”. in HÜE, Denis; FERLAMPIN-ACHER, Christine. (Eds.) - Enfances arthuriennes. Actes $d u 2^{e}$ colloque arthurien de Rennes, 6-7 mars 2003. Orléans: Paradigme, 2006, pp. 255-268.

14. Un ejemplo paradigmático se halla en la primera aventura que encuentra Arturo en su camino, la cual representa una mala costumbre. Cuando el joven caballero vence al adversario que había ganado, anteriormente, la justa del papagayo, Arturo expresa: “- Lyon, ce dist le roy, tu as moult malement gardé l'ordre de chevalerie, car chevalerie veult rayson et droiture a toutes gens; si as mieulx ensuÿ le nom que ton pere te mist que le nom qui te fust chargié quant tu fu chevalier nouveaux. Et si te diray comment: tu as tollu l'avoir aux chevaliers, qui de toy ne se pouoyent deffrendre, a grant tort. Et puis les as tenus en seigneurie et toutes leurs gens sans rayson et sans droiture, et de ce as tu bien suyvi le nom de Maulvais Garçon, mais le nom de Lyon non, car lion est la plus franche veste qui soit au monde, car il ne Saura ja avoir si grant fain ne ne será ja si irés vers nulle veste, se elle se couche a terre et luy monstre semblant d'umilité, que il la veuylle plus toucher des lors en avant. Et $\left[8 \mathrm{v}^{\circ}\right]$ pour ce as tu mal ensuÿ le nom de Lion". Le Conte du Papegau. Ed., trad. y notas de Hélène Charpentier y Patricia Victorin, p. 90.

15. The Parisiana Poetria of John of Garland. Ed. y trad. Traugott Lawler. New Haven: Yale University Press, 1974, I, 49, 100 [trans. 101].

16. Dos componentes esenciales de la actividad desarrollada por Arturo en esta historia.

17. Retomar motivos sobresalientes de la tradición artúrica (la justa del gavilán/papagayo; el episodio de la carreta, para mencionar algunos) es incentivar la buena recepción porque se supone que se escuchará aquello que ya se conoce.

18. En su estudio sobre el sermón francés durante el periodo 1215 a 1535, Larissa J. Taylor nos recuerda que este se originó en las órdenes mendicantes, circunstancia visible en el ethos presente en la forma, en el estilo y en el contenido de los exempla. Los mendicantes fueron eximios estudiosos de la naturaleza y psicología humana: el predicador hacía uso de la imaginación de su auditorio y de las imágenes, proveniente de diversas fuentes, para dramatizar sus temas. Taylor señala, además, que los exempla pueden distribuirse en cuatro categorías: historias de la Antigüedad, leyendas, poemas, fabliaux y romans, fábulas, descripciones provenientes de los bestiarios y eventos contemporáneos y/o anécdotas personales del predicador. La especialista comenta, por último, que si bien los exempla predominaban en los sermones de todos los tiempos, durante los siglos XIV y XV su empleo abusivo derivó en una campaña, por parte de los mismos predicadores, para reducirlos o eliminarlos del sermón. Sin embargo, dicha “predicación" resultó ser infructuosa, dado que los moralistas admitían el profundo valor pedagógico y de entretenimiento de los exempla. En mi opinión, esta misma combinación se encuentra en El Conte du papegau. Véase TAYLOR, Larissa J. - "French sermons, 1215-1535". in MAYNE KIENZLE, B. (Ed.) - The sermon. Turnhout: Brepols, 2000, pp. 711-758.

19. Los autores medievales de manuales morales, de literatura didáctica y de tratados médicos, concuerdan en dividir los diferentes estadios de la vida humana en tres etapas: 1) infantia, desde el nacimiento hasta la edad de 7 años, 2) pueritia, de 7 a 12, para las mujeres y de 7 a 14 para los varones y 3) adolescentia, de 12 o 14 hasta la adultez. Asimismo, la mayoría de los autores consideran un periodo post-adolescencia, el del 
juventus. SHAHAR, Shulamith - Childhood in the Middle Ages. London: Routledge, 1992, p. 22. Las representaciones de la juventud a las que hago referencia en este trabajo darían una imagen contemporánea de los miembros masculinos de la nobleza que se encuentran entre el final de la adolescencia y el principio de la juventud, es decir, en la frontera con la adultez.

\section{RESÚMENES}

Cuando el destino final del legendario rey Arturo estaba definitivamente sellado, un autor anónimo compuso un relato de sus mocedades. Primer intento conservado hasta el presente de ofrecer al anciano soberano ejemplar de la fabulosa Bretaña una posibilidad de demostrar, retrospectivamente, su talento caballeresco frente a oponentes excepcionales.

En este trabajo, se intentara demostrar, mediante el análisis de algunas marcas textuales, que el Conte du Papegau está destinado a un público juvenil y tiene como finalidad educarlos en las cualidades caballerescas y morales necesarias para todo joven de la nobleza.

When the fate of the legendary King Arthur was finally sealed, an anonymous author composed a story of his early years as sovereign. This was the first attempt - preserved up to the present that aimed to show retrospectively Arthur's knightly talent when facing exceptional opponents. Through the analysis of some textual marks, in this article we aim to demonstrate that the Conte $d u$ Papegau was intended for a young audience. Besides it had the purpose of providing education in the chivalrous and moral qualities expected and necessary for the youth belonging to the nobility.

\section{ÍNDICE}

Keywords: "enfance" litterature, exemplum, Arthurian romance, Late Middle Ages

Palabras claves: relatos de infancia, exemplum, roman artúrico, Edad Media tardia

\section{AUTOR}

\section{LIDIA AMOR}

Instituto Multidisciplinario de Historia y Ciencias Humanas (IMHICIHU) - CONICET, Buenos Aires, Argentina

Facultad de Filosofía y Letras, Universidad de Buenos Aires, Buenos Aires, Argentina

lidiaamor@conicet.gov.ar

https://orcid.org/0000-0003-4414-4148 